\title{
COMMENT
}

\section{Quantifying the decline in Corallium rubrum populations}

\author{
Giovanni Santangelo ${ }^{1, *}$, Lorenzo Bramanti ${ }^{1,2}$ \\ ${ }^{1}$ Department of Biology, University of Pisa, Via Volta 6, 56126 Pisa, Italy \\ ${ }^{2}$ Institut de Ciencies del Mar, Passeig Maritim de la Barceloneta 37-49, 08003 Barcelona, Spain
}

\begin{abstract}
A recent article by Bruckner (2009; Mar Ecol Prog Ser 397:319-332) focused on population decline in the commercially exploited Mediterranean red coral Corallium rubrum. Bruckner (2009) used data on coral size structure and reproductive output gathered by a variety of sampling methods in different populations: Data on overharvested shallow-water populations (which are generally made up of crowded, small-sized colonies) were combined with the small amount of data available on deep-water populations (which consist of larger, sparse colonies); the latter have become the main target for commercial harvesting nowadays. In our opinion, the conclusions in Bruckner (2009) did not fully reflect the heterogeneity and the limits of the data set. Collection of sound demographic data through broader, coordinated research applying standard procedures to different populations is required for a reliable analysis of Corallium rubrum population dynamics.
\end{abstract}

KEY WORDS: Gorgonians · Red coral · Mediterranean Sea · CITES Appendix II listing

\section{INTRODUCTION}

The best means to reconcile the exploitation and conservation of precious long-lived octocorals is a matter of some controversy (Tsounis et al. 2010). A demographic approach based on sound population data could foster their rational exploitation (Santangelo et al. 2007). Although several species of the genus Corallium are currently exploited (Bruckner 2009), the Mediterranean red coral Corallium rubrum, which has been harvested for $>2000 \mathrm{yr}$, is the most precious and extensively studied. However, research is mainly limited to shallow-water populations, i.e. those between 10 and $50 \mathrm{~m}$ depth. These easily accessible colonies have long been subject to overharvesting - which in a few isolated cases persists today (Tsounis et al. 2007) and are characterized by small, crowded colonies of low commercial value. The more valuable populations currently being harvested are deep-water ones between 70 and $150 \mathrm{~m}$ depth, whose colonies reach larger sizes. As the demographic features of deepwater populations are largely unknown (Rossi et. al.
2008), the article by Bruckner (2009) is based mainly on studies dealing with shallow-water populations. Extending these findings to all red coral populations and trying to draw general conclusions on population trends on a Mediterranean-wide scale cannot but lead to erroneous conclusions.

One of the main difficulties in comparing red coral population data regards the heterogeneity of the sampling methods employed by different researchers. Only recently has a concerted effort been made by Mediterranean red coral researchers to standardize the sampling regime (Santangelo et al. 2009, Tsounis et al. 2010).

\section{ASSESSMENT OF POPULATION STRUCTURE BY DIFFERENT SAMPLING METHODS}

Bruckner (2009) compares the size-frequency distribution of red coral colonies of 5 populations studied by Garcia Rodriguez \& Massò (1986), Garrabou \& Harmelin (2002), Santangelo et al. (2003, 2007), Tsounis et al. (2006, 2007), Rossi et al. (2008). An important 
limitation of his analysis stems from the different way in which populations were sampled. In his 'Materials and methods', Bruckner (2009, p. 323) admits that 'size frequency distribution varies between studies depending on the methodology used', but in his further analysis he does not take this into account and compares percentages which are not comparable (Fig. 5, Table 3). Only one shallow population (Calafuria, Italy) has been completely sampled (recruitment included); the average diameter of red coral recruits was $0.6 \mathrm{~mm}$ (Bramanti et al. 2005) and they could only be identified on microphotographs or through analysis of an entire scraped-off rocky surface (Santangelo et al. 2007). All other populations have been sampled by different methods, in a selective way, and small size classes were underrepresented or not sampled at all. Concerning the 'historic population' data in Bruckner (2009), collection of these colonies was almost certainly biased, as it was done by commercial trawling and SCUBA diving. Due to the sampling selectivity, it is inappropriate to calculate percentages of colonies in the different size classes (Bruckner 2009, his Fig. 5A,B), since the datasets do not include or underestimate a variable number of size classes. In any case, as we can reasonably assume that larger colonies were unselectively harvested or sampled in all studies, it would only be appropriate to compare among populations the numbers (not percentages) of larger colonies in the decreasing, right shoulder of the curves.

\section{CALCULATION OF REPRODUCTIVE OUTPUT WITHOUT POPULATION DENSITY DATA}

A second problem concerns the area sampled in the different studies analyzed by Bruckner (2009); in several cases no density data were reported. Data on density, as well as on population size structure, are fundamental to calculating population reproductive output. Different populations with the same size structure but different densities may have highly different reproductive outputs. Bruckner (2009, p. 322) states that 'density estimates were not available for most locations' but fails to take this limitation into account in his Table 3. Without data on population density, reproductive output cannot be compared among populations.

\section{OTHER CONTROVERSIAL STATEMENTS}

Bruckner (2009, p. 319) states: 'Today, $>90 \%$ of colonies in fished areas are 3 to $5 \mathrm{~cm}$ tall [and] $<50 \%$ are sexually mature'. Both statements require qualification, as the cited size values refer only to shallow-water populations. Only one of these populations (Cap de
Creus) - which consists of small colonies located in a marine protected area - is still overharvested (Tsounis et al. 2007). Nowadays, mainly deep-water populations are harvested commercially, as the market value of their larger colonies (10 to $50 \mathrm{~cm}$ high) is about $20 \times$ greater than that of shallow-water colonies. Bruckner (2009) uses data from shallow-water populations to draw inferences on those in deep water. Immature colonies (including recruits) can represent $>50 \%$ of shallow-water populations (Santangelo et al. 2007), a structure that is typical of 'steady state' populations, in which younger classes are inevitably more abundant than older ones; this monotonically decreasing structure is not a symptom of population decline. Nothing is known on the reproductive structure of deep-water populations.

Bruckner (2009, p. 329) further states: ' ... a shift from historic measures of 20 to $50 \mathrm{~cm}$ to $<5 \mathrm{~cm}$ in height is equivalent to a loss of 80 to $90 \%$ of the reproductive modules of individual colonies'. This statement is based on the previous one, and once again mixes values for shallow- and deep-water populations. Although it is reasonable to assume that shallow-water populations, which are nowadays made up of small but crowded colonies, were once structured differently - with some larger colonies, but lower densities (Garrabou \& Harmelin 2002, Bramanti et al. 2009) we cannot say how this decline (corresponding to a reduced life-span?) actually occurred, as we have no data on their structure and density in the past. Thus, there is no basis for calculating an 80 to $90 \%$ decline in the number of polyps (reproductive units), one of the main points in Bruckner (2009). Current shallow-water populations reach high colony densities, and consequently high polyp densities. Moreover, in the Calafuria population a clear density dependence of recruitment was found (Santangelo et al. 2007), with 2 opposite trends: at low colony densities the recruits/ larvae ratio increases with density, while for higher densities it falls proportionally. Density dependence has also been reported for other shallow-water populations (Garrabou \& Harmelin 2002). A population decrease or extinction is to be expected only when the reduction in the number of large colonies is not balanced by an increase in recruitment and by high density of small colonies (Bramanti et al. 2009).

Finally, Bruckner (2009, p. 319) states: 'Minimum allowable size for harvest should be increased because traditionally determined growth rates appear to underestimate colony age'. The author judges that, as colony growth rates have been overestimated in the past, the minimum legal size for harvesting should be increased. This rather weak argument can be countered by considering that if colony growth rate is lower, the number of years and reproductive cycles needed to reach the fixed legal size will naturally rise, as will the number of 
reproductive cohorts in a population. Although Bruckner's claim is not underpinned by science, a precautionary approach to coral exploitation would require increasing the allowed minimum colony size.

\section{CONCLUDING REMARKS}

The analysis of the decline in Corallium rubrum populations is presently constrained by inappropriate comparisons of data that have been gathered by different methods. As population densities are not known, it is not possible to calculate their reproductive output.

Bruckner (2009) fails to take into account the current diversification of today's red coral populations, which can be schematically divided into shallow-water populations, and deep-water ones currently undergoing commercial exploitation. We know very little about the latter, as little research has been carried out on them.

After working on red coral for many years, it is difficult to admit that the available datasets cannot be easily compared, and that we still do not know enough about the demography of exploited populations. The article by Bruckner (2009) highlights the need for coordinated research at a Mediterranean scale. Only a proper sampling plan will enable an application of demographic tools to the management of this precious and beautiful species.

\section{LITERATURE CITED}

Bramanti L, Magagnini G, DeMaio L, Santangelo G (2005) Recruitment, early survival and growth of the Mediterranean red coral Corallium rubrum, a four-year study. J Exp Mar Biol Ecol 314:69-78

Editorial responsibility: Karen Miller, Hobart, Tasmania, Australia
Bramanti L, Iannelli M, Santangelo G (2009) Mathematical modelling for conservation and management of gorgonians corals: youngs and olds, could they coexist? Ecol Model 220:2851-2856

> Bruckner AW (2009) Rate and extent of decline in Corallium (pink and red coral) populations: existing data meet the requirements of a CITES Appendix II listing. Mar Ecol Prog Ser 397:319-332

Garcia-Rodriguez M, Massò C (1986) Estudio biometrico de poblaciones de coral rojo del litoral de Gerona. Bol Inst Esp Oceanogr 3:65-74

Garrabou J, Harmelin JG (2002) A 20-year study on lifehistory traits of a harvested long-lived temperate coral in NW Mediterranean: insights into conservation and management needs. J Anim Ecol 71:966-978

Rossi S, Tsounis G, Orejas C, Padrón T and others (2008) Survey of deep-dwelling red coral (Corallium rubrum) populations at Cap de Creus (NW Mediterranean). Mar Biol 152:429-439

Santangelo G, Carletti E, Maggi E, Bramanti L (2003) Reproduction and population sexual structure of the overexploited Mediterranean red coral Corallium rubrum. Mar Ecol Prog Ser 248:99-108

Santangelo G, Bramanti L, Iannelli M (2007) Population dynamics and conservation biology of the over-exploited Mediterranean Red coral. J Theor Biol 244:416-423

Santangelo G, Bramanti L, Vielmini I, Iannelli M (2009). What we have learned about red coral and what we need to learn for its rational management. In: Bruckner A, Roberts G (eds) 1st Int Workshop on Corallium science, management and trade, Hong Kong, 2009. NOAA Tech Memo NMFS-OPR-43:71-86

Tsounis G, Rossi S, Gili JM, Arntz WE (2006) Population structure of an exploited benthic cnidarian: the case study of red coral (Corallium rubrum). Mar Biol 149: 1059-1070

Tsounis G, Rossi S, Gili JM, Arntz WE (2007) Red coral fishery in the Costa Brava (NW Mediterranean): case study of the overharvested precious coral. Ecosystems 10:975-986

Tsounis G, Rossi S, Grigg R, Santangelo G, Bramanti L, Gili JM (2010) The exploitation and conservation of precious corals. Oceanogr Mar Biol Annu Rev 48:161-212

Submitted: August 10, 2010; Accepted: October 18, 2010 Proofs received from author(s): November 3, 2010 